\title{
Unmet healthcare needs for older people attending the outpatients' clinics of a university hospital in Cairo, Egypt: a qualitative study
}

\section{Original Article}

Shaimaa A.M. Abd El-Fatah

Public Health and Community Medicine Department, Faculty of Medicine, Cairo University, Giza, Egypt

\begin{abstract}
Background: Egypt is experiencing significant changes in age structure mostly among the older population, which is expected to quadruple over the period 2010-2050. There is no easy, quick-fix recipe for elders' health needs assessment. Qualitative methods are required to explain what is already known. This study aimed to assess the unmet healthcare needs of the elders attending the outpatients' clinics of the Cairo University Hospital.

Patients and Methods: A qualitative design with a thematic content analysis of semistructured interviews was used to assess the unmet healthcare needs of elders above 60 years of age, attending the outpatients' clinics of Cairo University Hospital.

Results: The most bothersome complaints were the overcrowding and abnormally long waiting times followed by the falsely claimed free of charge governmental services. Besides, the lack of outpatient long-term management was coupled with the fact that some of the needed health services were unavailable, not easily accessible, and insufficient. Moreover, worthless dealing was the most prominent theme in patients' opinions regarding bad healthcare providers, starting from verbal or nonverbal aggression and prejudice to inadequate information provision for the improvement of elders' health. Conclusion: Problems facing older patients in the outpatients' clinics included lack of follow-up services, fractional treatment by the health providers, and absence of internal complaints mechanism. Their suggestions for improvement focused on improving the communication skills of healthcare providers and establishing continuity of the care system. Inevitable improvements in the clinics' services include: establishment of a geriatric clinic with a multidisciplinary clinical team in addition to enhancing communication and health education with the elders, negotiating to arrive at the best therapeutic options, and fostering motivation and skills needed for self-care.
\end{abstract}

Received: 06 May 2017, Accepted: 11 February 2018

Key Words: Elders, outpatients' clinics, unmet health needs.

Corresponding Author: Shaimaa A.M. Abd El-Fatah, MD, Public Health and Community Medicine Department, Faculty of Medicine, Cairo University, 12 Manial Street, Giza, Egypt, Postal Code:11451, Tel.: +20 1003062047 , E-mail: drshaimaali595@hotmail.com

Journal of the Egyptian Public Health Association, ISSN: 0013-2446, Vol. 92, No.4

\section{INTRODUCTION}

Egypt is experiencing a rapid pace aging process owing to continuing declines in mortality, combined with recent rapid declines in fertility. This new emerging demographic phenomenon requires adoption of new strategies to secure a better quality of life for the aging population $[1,2]$. Providing high-quality, cost-effective healthcare to older adults, especially those with multiple comorbidities, is an increasingly serious challenge for healthcare systems [3].

Assessment of health needs is not simply a process of listening to patients or relying on their personal experience. It is a systematic method of identifying the unmet healthcare needs of a population and making changes to meet these unmet needs. It involves an epidemiological and qualitative approach to determine priorities, which incorporates clinical, cost effectiveness and patients' perspectives [4].

Needs assessments, as a basis for provision of care, usually focus on older persons' adjusted daily living capacity, cognitive ability, and informal care, while health complaints and social needs are less in focus [5].

Considerable evidences indicate that Egyptian elders with multiple comorbid conditions receive suboptimal preventive care services, and disease-centric care approaches in the outpatients' clinics which may lead to undesirable outcomes $[6,7]$. This study aims to investigate the unmet health needs of some of the older attendants of Cairo University (CU) Hospital outpatients' clinics and to identify the causes of their dissatisfaction.

\section{PATIENTS AND METHODS}

Study setting

This study was conducted in the outpatients' clinics of CU hospital. It took place over 3 months starting from January 2017.

\section{Study type}

A qualitative research design with thematic content analysis of semistructured interviews with older people attending the outpatients' clinics. 


\section{Study participants and recruitment strategy}

Purposeful sampling was used to recruit informant older participants. It was a maximum variation sampling, that is, from both sexes and different clinics. Twenty-eight older patients who were above 60 years of age, who accepted to participate were recruited. The inclusion criteria were chronically ill older patients irrespective of the type of illness or the visited clinics, or any sociodemographic factors.

\section{Data collection}

The researcher conducted individual semistructured face to face interviews in Arabic, which were then translated into English. Interviews lasted from 18 to $47 \mathrm{~min}$ (average $31 \mathrm{~min}$ ) The interviews began with an open-ended question based on the major research question and continued with follow-up questions about the problems of the delivered health services provided by the outpatients' clinics.

Furthermore, probing questions were asked to the participants during the interviews to make the answers clearer.

When targeting older patients, to ensure that the interviews were comprehensible and well organized, the first two interviews served as pilot interviews. For this process, the participants were asked to provide feedback on the clarity and structure of the questions. Interviews were also analyzed for interviewer interaction with the participants. Following these pilot sessions, minor revisions were made to the interview guide including changes to questions order, and a reduction in perceived repetition of interview themes. Since the pilot participants expressed good understanding of the research goal and questions, and the researcher judged that their responses did not substantially differ from later participants, their responses were included in the final analysis.

\section{Study tools}

All the interviews were recorded by a voice recorder with permission from the participants, and then were transcribed verbatim after each meeting. Interviews were anonymized, and the audio recordings and transcriptions were stored on a password-protected computer.

The sociodemographic backgrounds of the interviewees were inquired upon, including their age, sex, education, occupation, and health insurance. Themes of the older patients' interviews were constructed after a thorough review of the literature [8-10]. The interview guide, included six open-ended questions, asked and adapted flexibly to fit with the elderly responses about categories of 'unmet healthcare needs' (Appendix 1) [10].

\section{Data analysis}

Thematic content analysis method was applied. After the researcher was sure that no new data emerged, and that the data reached saturation, the data analysis process was started. Data saturation was monitored by evaluating the frequency of new codes with subsequent interviews. Once saturation was achieved (patient no. 28), the frequency that each code was mentioned was noted.

Data were scrutinized and arranged based on the main subjects and themes using the five stages suggested by Graneheim and Lundman as follows: (a) transcribing the whole interview immediately after completion; (b) reading the text to gather an overall understanding of its content; (c) determining the meaning units and initial codes; (d) classifying initial codes into more comprehensive categories, and finally (e) determining the hidden content of the data [11]. In this study, after every interview, the contents were transcribed, typed, and read several times to extract initial codes. The codes were combined according to similarities to form categories, and finally the hidden concepts and content of data were extracted. To increase the reliability of data, the interview texts and a list of categories were revised by other colleagues who had experience in qualitative research. To increase credibility of the final findings, they were later reviewed by an outpatients' clinics physician and a nurse who did not participate in the study, based on their own experiences.

\section{Ethical considerations}

This study was approved by the administration of the outpatients' clinics. Emphasis was made that the implementation of the study will neither disturb the velocity of the work nor cause any harm to the studied elders. Before starting each interview, an oral informed consent was taken from each interviewee. All participants were informed about the objectives and method of the study. The researcher ensured that the participants clearly understood the study aims to give informed consent, particularly as some were unable to read. Participation was voluntary; therefore, they could refuse to participate or withdraw at any time. Moreover, they were reassured that their responses would be kept confidential and their identities would not be revealed in research reports and publications of the study.

\section{RESULTS}

Sociodemographic information of the older participants: interviews were carried out with 14 men and 14 women, who were divided into three age groups as follows: 17 participants (60-64 years), eight participants (65-74 years), three participants ( $>75$ years). The mean age of the participants was 64 years. Most of the participants (64.8\%) were illiterate, on pension (78.6\%) and $21.4 \%$ were currently working (whether manual work or office job). All participants had no health insurance (Table 1). 
Table 1 Sociodemographic characteristics of the study participants

\begin{tabular}{lc}
\hline Sociodemographic variables & $\mathrm{n}(\%)$ \\
\hline Sex & $14(50)$ \\
Males & $14(50)$ \\
Females & \\
Age groups & $17(60.8)$ \\
$60-64$ & $8(28.5)$ \\
$65-74$ & $3(10.7)$ \\
75 & \\
Education & $18(64.3)$ \\
Illiterate & $6(21.4)$ \\
Read and write & $2(7.1)$ \\
Primary & $1(3.6)$ \\
Preparatory & $1(3.6)$ \\
Secondary & $0(0)$ \\
High education & \\
Occupation & $22(78.6)$ \\
Pension & $4(14.3)$ \\
Current manual & $2(7.1)$ \\
Current office job & \\
Health insurance & $28(100)$ \\
No & \\
Yes & \\
\hline & \\
Total & \\
(10) & \\
\hline
\end{tabular}

Based on the older participants' experiences, themes were conceptualized and grouped according to categories of 'unmet needs' (Table 2). Representative statements that were not too long and that can be understood when separated from the context were selected.

Table 2 Main themes of this study on the basis of categories of unmet needs

\begin{tabular}{|c|c|}
\hline Categories of 'unmet needs' & Themes \\
\hline $\begin{array}{l}\text { Category 1: unperceived unmet } \\
\text { needs(did not perceive their need for } \\
\text { long-term basis or follow-up care) }\end{array}$ & $\begin{array}{l}\text { No outpatient care on the basis } \\
\text { of long-term management }\end{array}$ \\
\hline \multirow[t]{3}{*}{$\begin{array}{l}\text { Category 2: not demanding the health } \\
\text { services available }\end{array}$} & $\begin{array}{l}\text { Lack of culturally acceptable } \\
\text { services }\end{array}$ \\
\hline & $\begin{array}{l}\text { Improper behaviors of some } \\
\text { healthcare providers }\end{array}$ \\
\hline & $\begin{array}{l}\text { Insufficient information given } \\
\text { about a patient's health status }\end{array}$ \\
\hline $\begin{array}{l}\text { Category } 3 \text { : barriers to demanding or } \\
\text { receiving the service }\end{array}$ & $\begin{array}{l}\text { Needed health services } \\
\text { are unavailable; not easily } \\
\text { accessible and insufficient }\end{array}$ \\
\hline \multirow[t]{2}{*}{ Category 4: unmet needs for quality care } & Ineffective or poor quality care \\
\hline & False free of charges services \\
\hline \multirow[t]{4}{*}{ Category 5: unmet expectations } & $\begin{array}{l}\text { Overcrowdings, jam, and } \\
\text { abnormally long waiting times }\end{array}$ \\
\hline & $\begin{array}{l}\text { Absence of internal complaints } \\
\text { mechanism }\end{array}$ \\
\hline & Absence of 'clear' guiding marks \\
\hline & $\begin{array}{l}\text { Prospects and suggestions to } \\
\text { improve care of the clinics }\end{array}$ \\
\hline
\end{tabular}

\section{Category 1: unperceived unmet needs}

An individual does not perceive that he needs healthcare, like having diseases without symptoms or having complicated diseases. This type of unmet needs requires clinical investigations for detection.

Not receiving outpatient care on the basis of longterm management; only few participants had 'follow-up services':

'In some clinics "follow up" services are provided (e.g. family medicine clinic) while other clinics don't .... Unless I'm and my caregiver are interested and insistent to have the "follow up" services, I won't have them'. Male, 63 years old participant said.

\section{Category 2: not demanding the health services available}

An individual perceives himself as in need of some form of health intervention, but chooses not to demand the health services available. Underuse or nonuse is an individual's choice and preference. Individuals' choices may be due to lack of culturally acceptable services.

Healthcare providers (HCPs) don't treat patients 'properly' several older participants complained from bad HCP behaviors:

'I'm "a number" in the eyes of "bad" HCPs whether doctors or nurses...they're very busy and having no time for patients. Medicine is only a means of income and wealth in the eyes of "bad" HCP'. Female, 65 years old participant said.

Older patients even reported worse behaviors such as verbal and nonverbal aggression from some HCPs:

'The nurse shouted at me....they talk quickly and wave their hands. 'Male, 60 years old participant said.

Older patients and their families sometimes perceived 'prejudice' from service providers:

'I quarreled with the nurse because she allowed someone else to bypass me in line and see the doctor before me....Patients who have "intermediary" will see the doctors faster and nobody shouts at them!!' Female, 65 years old participant said.

Insufficient information provided for improvement of elders health:

'Only when we ask... doctors answer, mostly, all what they care about is to tell the diagnosis not the causes behind the disease or prevention.... They don't tell unless you ask. Few doctors tell you the whole story behind the illness and how treatment is done correctly and improvement might occur. 'Male, 61 years old participant said.

\section{Category 3: barriers to demanding or receiving the} service

An individual perceives himself as in need of some form of health intervention, but does not receive health 
services because of access barriers beyond his control. For example, poor individuals living in remote areas may not be able to afford to travel to a healthcare facility when needed or if services were too expensive, such information enhances our understanding of inequity in healthcare utilization.

The needed health services are unavailable, not easily accessible, and insufficient:

'In some clinics, the needed investigations are either delayed or not done due to long waiting lists or expensive costs'. Male, 65 years old participant said.

'I usually dispense insufficient drugs amounts from the clinics' pharmacy and have to buy the rest from outside. Most patients have to perform certain laboratory or radiological investigations or endoscopy very late or outside the clinics funded by "charity centers". Female, 63 years old participant said.

\section{Category 4: unmet need for quality care}

An individual perceives a need for healthcare, accesses healthcare but does not receive the treatment that a clinician would judge as appropriate. Lower socioeconomic groups were more likely to receive ineffective or poor quality care.

The falsely claimed free of charge services' since financially; most patients that attend outpatients' clinics are of low socioeconomic levels, that is, poor patients, all interviewees universally agreed that:

'They (officials) deceived us by the apparent; unreal; falsely presented free services .... for example; the medications dispensed in the outpatients' pharmacy are cheap but of low quality and insufficient for treatment. Any good; prescribed medication should be brought from outside the clinics. 'Male, 60 years old participant said.

"Any delicate or complicated investigation ......must be done either "outside the clinics" or at "the expense of Ministry of Health (MOH)" or funded by charity people'. Female, 63 years old participant said.

'Over years; the small money "poor budget" allocated for care of people's health have resulted in this "Fake Gratuitous" show!!. 'Male, 61 years old participant said.

\section{Category 5: service quality not meeting expectations}

An individual perceives himself as in need of some form of health service, and he accesses care, but in his own perception does not receive the most suitable care.

The most bothersome complaint for the majority of elders participants were the overcrowdings, mess, and abnormally long waiting times:

'The overcrowdings and waiting times are extreme.... I waited for $4 \mathrm{~h}$ to be able to see the doctor for examination or for follow up, some patients' queue number is 50 !! 'Male, 67 years old participant said.

'Straying and roaming in the big outpatient clinics to reach the clinic of interest .... no "clear" guiding marks is especially irritating to illiterate older patients. 'Female, 75 years old participant said.

'Clinics don't have an "internal complaints mechanism" in the interest of the patient, patients don't know where to go if they want to complain face to face....to someone responsible. 'Male, 63 years old participant said.

\section{Prospects for clinics improvement}

(1) Good human communication skills: 'Good dealing' was the most prominent theme in patients' opinions. All interviewees universally agreed upon:

Good doctor or nurse should be characterized by: helping the patients by all means like (guidance and referral), easier to talk to him, -listening really well, taking sufficient time in examination and describing medications. 'All participants (all ages and both sexes) agreed.

'Other characters included: making you feel relaxed calling you by first name-inducing you to talk to him and you could have a laugh with him as well. 'Male, 60 years old participant said.

(2) The continuity of care (long-term care was central to the perception of the quality of the clinics' healthcare:

'I believe long term personal care ... over the years... establishes good doctor-patient relationship“. Male, 63 years old participant said.

'The doctor who follows me, knows the condition from the start to the end ....he knows the whole story ......I'm completely relaxed with him because I know I'm not a number!!'Female, 65 years old participant said.

(3) Integration of geriatric health services, suggestions included:

"Establishing a "new clinic" in a middle site between all clinics for older patients, it should have doctors delegated from the most common specialties dealing with elders; trained nurses and social workers. This will be an excellent, important service to minimize older patients suffering since they are already exhausted, fatigued. This is achieved through minimizing movement and wandering in the spacious outpatients' clinics. 'Male, 67 years old participant said.

"Establishing Ministry of Health "MOH office" in the clinics for the patients who are referred from $\mathrm{MOH}$ with "written consent for examination or treatment at the expense of the government".... if happened it will be an excellent, new, important service to minimize elders suffering. This is achieved through increasing cooperation between $\mathrm{MOH}$ and Cairo University hospitals. Thus minimizing "governmental routine steps" and finally minimizing patients' errands. 'Male, 60 years old participant said. 'Establishing a 'new banking account' for the new clinic to collect donations from all society (persons and organizations) to minimize budget constraints. 'Female, 65 years old participant said. 


\section{DISCUSSION}

The merits of qualitative approach are evident in the current study since the participants usually expressed a range of emotions, such as grief, anger, hatred, and depression. The interviews were often very emotionally charged. Also, repeated access to recordings for checking transcriptions enhanced the understanding of their problems and their views for improvement [11]. The qualitative approach was best able to capture the full range of practical, communicative, and emotional complexities associated with open disclosure, and it enabled repeated access to recordings for the purpose of checking transcriptions. The interviews with the patients in the present study were often very emotionally charged and challenging to manage, with participants expressing a range of emotions, including anger, hatred, and depression.

The most bothersome complaint for the majority of elders regarding the quality of service in the outpatients' clinics was the overcrowdings, the messy environment, and excessively long waiting times. This was logically explained since the CU hospital is a large, tertiary hospital with almost all specialties, receiving patients from all over Egypt. Meanwhile, absence and inadequately equipped clinics and hospitals in other governorates pushes people from these governorates to the capital seeking adequate health services. Such findings are consistent with many studies which investigated the factors associated with healthcare utilization by the elders. In terms of outpatient contacts, elders usually felt they needed more medical care, or other type of treatments they were not receiving (i.e. care was partly good or inappropriate) $[6,7,12]$.

The second most bothersome complaint was the falsely claimed free of charge services since financially most patients who attend outpatients' clinics are of low socioeconomic levels. They discovered that the costs of most medications and investigations required are more than they can afford. A lot of Egyptian studies were done to investigate the conditions of poor Egyptians [13-15]. Low earnings level is not the only feature of poverty, since it is also associated with malnutrition, poor housing conditions, limited access to basic services of water and sanitation, and consequently higher incidence of morbidity. Another factor aggravating the problem was that the government did not make enough of an effort to create a social security net for the lower and middle classes in Egypt to improve their health conditions [2]. All of the studied elders are without health insurance. This reflects the defects in the public old-age social insurance programs, in accordance with the 2009 United Nations Conference, which reported that in the developing countries, health insurance programs cover a much smaller fraction of workers than in most developed countries. For example, public pension and health insurance coverage are restricted to certain categories of workers such as public sector employees, highly educated citizens, and military personnel [15].
The third complaint was related to the 'bad treatment by the health providers'; elders and their families reported behaviors such as impatience, verbal, and nonverbal aggression, and abruptness from doctors and nurses. The dominant complaint reported by interviewees was 'a feeling of discrimination. Overall; all these mentioned findings are consistent with similar qualitative studies, done to explore the difficulties in doctor-patient relationships. 'Bad' doctors broke the 'caring' rule by 'not being bothered', not listening to patients, or not acknowledging their concerns. Being very busy, having no time for patients, and seeing medicines solely as a means of income all represent the characteristics of a bad doctor [16].

Regarding lack of follow-up services; many elders did not receive 'long-term chronic care', only few of them had 'follow-up services'. This finding is consistent with Dowrick and colleagues who investigated both opinions of patients and HCP (doctors and nurses). Elders generally agreed with doctors on the importance of follow-up and taking a holistic approach in healthcare. They believed that patients' coping abilities, social situation, and previous mental health are all important factors in determining management. The observed higher utilization among the elders is likely due to the higher prevalence of chronic disease and multimorbidity [13]. Concerning the frequency of follow-up visits to the clinics, studies have shown that it is not the aging of population that threatens healthcare systems, but rather the continuous increase in per capita utilization $[10,16]$.

Moreover, other studies recommended frequent and regular visits: to develop a partnership with the patient, establish an appropriate care plan, communicate and coordinate different specialties to integrate the patient's care, and educate the patient. Consequently, more visits are required at first; thus, the initial costs are more than the customary costs. But, this will prevent future emergency room encounters. As the patient's condition improves and stabilizes, the patient should be seen less often, although still on a regular basis [13].

Lack of good patient-provider communication was evident, since only some patients and their caregivers were involved in deciding the management plan. Informed decision-making should be used in the clinics. This simply means the doctors should share management decisions with patients. This finding is in line with other studies which stated that the patient and the caregiver must have the opportunity to ask questions and provide feedback into the incident (e.g. disease-investigation process) [14-17]. In developing countries, like Egypt, the socially disadvantaged groups have poor health literacy, commonly associated with distrust in HCP, lower self-management skills, and decreased self-efficacy. These groups also receive less preventive care and poorer quality of chronic care overall [14].

Clinics do not have an 'internal complaints mechanism,' 
which is easily accessible to patients, caregivers, and is effective in solving their problems. The findings regarding the experiences with $\mathrm{HCP}$, whether satisfaction or dissatisfaction, could be explained within the context of a prevalent Egyptian mentality. Dissatisfaction with the provided services and HCP may be attributed to the fact that old age is associated with reduced functional reserves and consequently decreased adaptation to any sort of external or even internal stressors, that is, loss of a person's ability to withstand environmental stresses (e.g. clinics' stress). Thus, a high percent of complaining was expected, specifically, the $75+$ elders who are more bold and valiant. They feel after all their life experiences, they have nothing to lose. On the other hand, satisfaction is expected within the traditions and culture of our Egyptian community where the patients are usually reluctant to express any dissatisfaction with any part of the provided services, especially in the clinics' atmosphere (for fear of persecution). In this context, it is assumed that the patients might feel many defects, but refuse to express them, especially since they cannot receive other services elsewhere (due to their poverty) $[14,15,18,19]$. On the other hand, elders may be unaware of their rights due to their poverty, and low educational and social class. So, they express their satisfaction with poor or even bad services (e.g. most patients would be satisfied with the service if the physician prescribes medication irrespective of the quality of other aspects of the service). Most of the studied older patients who attended the outpatients' clinics (59\%) had financial problems regarding obtaining the usual medical care. So the outpatients' clinics represent an available, cheap source of medical care [17].

The aforementioned findings are consistent with a similar Egyptian study done by Sedrak in CU hospital who assessed customer satisfaction using both 'client satisfaction questionnaire' and 'focus group discussions'. She found that the majority of cases gave positive answers to satisfaction questionnaire, while in-depth discussions revealed their sufferings and troubles during obtaining the services [20]. Again, this discrepancy is explained in light of the Egyptian mentality, characterized by calmness, patience, and high degrees of accommodation and adaptation with bad life and unhygienic environmental conditions. Frugality, saving, health negligence, and dependence on God's will are another set of characteristics of Egyptian low and middle social classes, which constitute most of our study participants [6].

Good human communication skills: 'good dealing' was the most prominent theme in patients' prospects for improvement. Social talk and appropriate use of humor must be used. Hope and advance care planning are mandatory. Previous studies have shown that HCP should help elders to imagine possibilities for their future and give them hope by providing information. Information should be about their illness, prognosis, and, specifically, how interventions could sustain their roles and relationships. Having HCP who see them in the context of their personal lives enhances the patient-physician relationship [20-22].
The continuity of care was central to many opinions about improving clinics' healthcare. Findings regarding appropriateness and organization of care (receiving care needed from doctors, caretakers, psychologists) are consistent with studies like that of Mohamed [18] who investigated patients' expectations and satisfactions in different Egyptian hospitals. He found that $67 \%$ of the participants believed that urgent additional efforts are needed to organize care. The patient should become familiar with the provider (doctor or nurse), and the provider should have the opportunity to develop personal knowledge of the patient - for example, his or her illness, social circumstances, or family history - which help them to provide individualized and holistic care [23]. It is important for fostering trust and confidence, putting the patient at ease, facilitating open communication, and promoting better long-term management [24]. The solution of collection of geriatric health specialties and services in one clinic was addressing the problem of fragmentation, that is, the process of patient care has evolved into multiple tasks, encompassing the contribution of various physicians, nurses, and paramedics, who often work in different departments leading to difficulties in improving quality of care. This creates physical and psychological stress over the elders and their caregivers [6,25]. Minimizing movement and wandering of the elders in the big clinics to reach the service will promote better long-term management and follow-up services [26].

\section{CONCLUSION AND RECOMMENDATIONS}

The current study demonstrated that overcrowdings, falsely claimed free of charge services, bad treatment by the health providers, lack of follow-up services, and absence of internal complaints mechanism were the most bothersome complaints. Improving $\mathrm{HCP}$ communication skills and continuity of care were the most eminent suggestions provided by the elders to improve the clinics' performance. Adopting a comprehensive geriatric assessment approach by geriatric health clinics is particularly important to avoid any additional increase suffering of the already exhausted, fatigued older patients. This is achieved through a multidisciplinary clinical team, formed of doctors and nurses from many specialties in addition to dieticians and social workers for the diagnosis, treatment, follow-up of elders, and supplementing aids for the poor suffering from severe health or social problems. Motivating HCP to change their concepts about elders' care to promote health and function in older people, especially, respecting the patients' rights and dignity is another vital recommendation.

\section{Limitations of the study}

Being a qualitative study, data analysis can result in the decontextualization of speakers' words which may misrepresent the intended meaning as they appeared in the original sequential talk. The purposive sample does not represent the geriatric population attending the clinics. 
This limits the generalization of the findings. Recall bias is also common in the elders. The content analysis and creation of the themes was done by one researcher.

\section{ACKNOWLEDGEMENTS}

The authors acknowledge all the elders who agreed to participate and shared their opinions and future expectations.

\section{Conflicts of interest}

There are no conflicts of interest.

\section{APPENDIX}

Table A1 In-depth interview guide

\begin{tabular}{|c|c|}
\hline Main study inquiries & Six open ended questions \\
\hline \multirow[t]{5}{*}{$\begin{array}{l}\text { Problems facing older patients in } \\
\text { the outpatients' clinics }\end{array}$} & $\begin{array}{l}\text { What are your most bothersome } \\
\text { complaints whether from the } \\
\text { outpatients' clinics' system or the } \\
\text { working health care providers? }\end{array}$ \\
\hline & $\begin{array}{l}\text { What are your current unmet } \\
\text { needs from the outpatients' } \\
\text { clinics? }\end{array}$ \\
\hline & $\begin{array}{l}\text { What are the barriers that make } \\
\text { you personally choose not to } \\
\text { utilize certain outpatients' clinics' } \\
\text { services (although they are } \\
\text { present)? }\end{array}$ \\
\hline & $\begin{array}{l}\text { What are the barriers that are } \\
\text { beyond your choice (in the place), } \\
\text { preventing you from utilizing } \\
\text { certain outpatients clinics' } \\
\text { services? }\end{array}$ \\
\hline & $\begin{array}{l}\text { What are your unmet expectations } \\
\text { from the outpatients' clinics? }\end{array}$ \\
\hline $\begin{array}{l}\text { Prospects and suggestions to } \\
\text { improve care of the clinics }\end{array}$ & $\begin{array}{l}\text { How can the mentioned problems } \\
\text { be addressed (solved)? }\end{array}$ \\
\hline
\end{tabular}

\section{REFERENCES}

1. Ni Bhrolchain M. The demography and epidemiology of human health and aging. Popul Stud 2013; 67:248-252.

2. Rashad H, Khadr Z. Measurement of health equity as a driver for impacting policies. Health Promot Int 2014; 29:i68-i82.

3. Stock R, Mahoney ER, Reece D, Cesario L. Developing a senior healthcare practice using the chronic care model: effect on physical function and health-related quality of life. J Am Geriatr Soc 2008; 56:1342-1348.

4. Williams R, Wright J. Epidemiological issues in health needs assessment. BMJ 1998; 316:13791385 .
5. Karlsson S, Edberg AK, Hallberg IR. Professional's and older person's assessments of functional ability, health complaints and received care and service. A descriptive study. Int J Nurs Stud 2010; 47:1217-1227.

6. Khafajy G. The role of family physician in providing comprehensive geriatric assessment [MD dissertation]. Cairo, Egypt: Faculty of Medicine, Cairo University; 2010.

7. Mosad Z. The quality of health care and patient satisfaction: an exploratory investigation of the 5Qs model at some Egyptian and Jordanian medical clinics. Int J Health Care Qual Assur 2006; 19:60-92.

8. Boutayeb A, Boutayeb S, Boutayeb W. Multimorbidity of non communicable diseases and equity in WHO eastern mediterranean countries. Int J Equity Health 2013; 12:60-65.

9. Gott M, Ingleton C, Bennett MI, Gardiner C Transitions to palliative care in acute hospitals in England: qualitative study. BMJ 2011; 1:42-44.

10. Worth A, Irshad T, Bhopal R, Brown D, Lawton J, Grant E, et al. Vulnerability and access to care for south Asian sikh and muslim patients with life limiting illness in Scotland: prospective longitudinal qualitative study. BMJ 2009; 338:b183-b187.

11. Allin S, Grignon M, Le Grand J. Subjective unmet need and utilization of health care services in Canada: what are the equity implications? Soc Sci Med 2010; 70:465-472.

12. Graneheim UH, Lundman B. Qualitative content analysis in nursing research: concepts, procedures and measures to achieve trustworthiness. Nurse Educ Today 2004; 24:105-112.

13. Central Agency For Public Mobilization And Statistics(CAPMAS). Central statistical year book 2014. [cited 2016 March 2] Available at: https:// www.arabdevelopmentportal.com/ar/node/171282.

14. Ministry of Health and Population [Egypt], El-Zanaty and Associates [Egypt], and ICF International. Egypt Demographic and Health Survey 2014. Cairo, Egypt and Rockville, Maryland, USA: Ministry of Health and Population and ICF International; [cited 2016 March 2].

15. United Nations. World economic and social survey: promoting development, saving the planet. United Nations. [cited 2017 Dec 27]. Available at:https://www.arabdevelopmentportal.com/ar/ node/171282. 
16. Fernández-Olano $\mathrm{C}$, Hidalgo JDLT, Cerdá-Díaz $\mathrm{R}$, Requena-Gallego M, Sánchez-Castaño C, Urbistondo-Cascales L, et al. Factors associated with health care utilization by the elderly in a public health care system. Health Policy 2006; $75: 131-139$

17. Stokes T, Dixon-Woods M, Windridge KC, McKinley RK. Patients accounts of being removed from their general practitioners list: qualitative study. BMJ 2003; 326:1316-1320.

18. Mohamed MM. An empirical study of patients' expectations and satisfactions in Egyptian hospitals. Int J Health Care Qual Assur 2005; 18:516-532.

19. Khadr Z. Differences in levels of social integration among older women and men in Egypt. J Cross Cult Gerontol 2011; 26:137-156.

20. Sedrak A. Quality emergency obstetric care in Cairo university hospitals [MD dissertation]. Cairo, Egypt: Faculty of Medicine; Cairo University; 2012.

21. Khadr Z, Yount K. Differences in self-reported physical limitation among older women and men in Ismailia, Egypt. J Gerontol B Psychol Sci Soc Sci 2012; 67:605-617.
22. Dowrick C, Leydon GM, McBride A, Howe A, Burgess H, Clarke P, et al. Patients' and doctors' views on depression severity questionnaires incentivised in UK quality and outcomes framework: qualitative study. BMJ 2009; 338:b663-b669.

23. Davison SN, Simpson C. Hope and advance care planning in patients with end stage renal disease: qualitative interview study. BMJ 2006; 333:886889 .

24. Tarrant C, Windridge K, Boulton M, Baker R, Freeman G. Qualitative study of the meaning of personal care in general practice. BMJ 2003; 326:1310-1315.

25. Plochg T, Klazinga NS, Starfield B. Transforming medical professionalism to fit changing health needs. BMC Med 2009; 80:64-69.

26. Oprea L, Braunack-Mayer A, Rogers WA, Stocks N. An ethical justification for the chronic care model. Health Expect 2010; 13:55-64. 